\title{
Informações de Custos: um estudo em empresas hoteleiras na cidade de Florianópolis - SC
}

\section{Cost Information: a study in hotel companies in Florianópolis - SC}

\author{
Rogério João Lunkes ${ }^{1}$
}

\begin{abstract}
Resumo
O aumento da competitividade está levando os hotéis a aperfeiçoar seus sistemas de gestão, principalmente os relacionados a custos. É neste sentido que se desenvolve o tema do presente trabalho: apresentar os resultados de pesquisa sobre a existência de informações de custos em empresas hoteleiras da cidade de Florianópolis (SC). Assim, procura-se identificar e analisar um conjunto de informações e ferramentas de custos utilizadas pelas empresas hoteleiras, no aproveitamento das oportunidades e na minimização das ameaças decorrentes das mudanças do ambiente. Para tanto, faz-se uma breve revisão dos principais conceitos relacionados aos métodos de custeio, análise custo/volume/lucro, centros de responsabilidade e formação do preço da diária. $\mathrm{O}$ delineamento metodológico adotado para desenvolver esta pesquisa foi o descritivo, de caráter quantitativo e qualitativo, conduzido através do instrumento de levantamento (survey) e amostragem por acessibilidade. Os resultados revelam que $40 \%$ dos hotéis utilizam algum sistema de custeio.
\end{abstract}

Palavras-Chave: hotel; evidenciação; custos; centro de responsabilidade; preço.

\begin{abstract}
The increasing competitiveness is taking hotels to best adjust its management systems mainly those related to costs. The subject of this work is developed in this sense: to present research results obtained from the use of cost information in hotel companies in Florianópolis (SC) city. Thus, the research verifies how hotel companies understand and use their cost information to explore advantages and minimize threats resulting from environmental changes. This way, one brief revision is undertaken on the main concepts related to costing methods, analysis cost/volume/profit, responsibility center management and daily rate formation. To develop this research and achieve the main objective, a descriptive method was used throuch a survey and delineation by accessibility. The results reveal that $40 \%$ of hotels use some kind of costing system.
\end{abstract}

Keywords: hotel; disclosure; costing; responsibility center; rate.

\footnotetext{
${ }^{1}$ Graduado em Ciências Contábeis; Mestre e Doutor em Engenharia de Produção e Sistemas - PPGEP/UFSC. Professor do Departamento de Ciências Contábeis e do Programa de Pós-Graduação em Contabilidade da Universidade Federal de Santa Catarina. E-mail: lunkes@cse.ufsc.br
} 


\section{Introdução}

As condições da atividade empresarial estão em constantes mudanças. Entre essas mudanças podem ser destacadas as decorrentes da estrutura demográfica, do avanço tecnológico, do processo de globalização, da preocupação com o meio ambiente e do impacto das mudanças governamentais sobre a sociedade. Quanto às empresas hoteleiras, elas terão que oferecer experiências únicas e novas soluções às necessidades dos hóspedes e não apenas oferecer pernoites.

Assim, essas mudanças vêm deixando o setor hoteleiro em ebulição no Brasil, o que decorre da entrada de grandes redes de hotéis que tornam a hotelaria um dos terrenos mais férteis para a realização de negócios. Dados do Ministério do Turismo de 2005 mostram que atualmente cerca de US\$ 1,5 bilhão estão sendo investidos na expansão da estrutura hoteleira nacional. Essa movimentação também atinge os empreendimentos já consolidados, que buscam agora um diferencial competitivo.

Segundo dados de 2005 da ABIH (Associação Brasileira de Indústria Hoteleira), o Brasil tem 18 mil hotéis e pousadas, além de 7.500 outros meios de hospedagem, como albergues e alojamentos. A oferta de unidades habitacionais ultrapassou os 343 mil em 2005, contra 310 mil em 2004 e 140 mil em 1992. A expectativa é de queda da taxa de ocupação em determinadas regiões. Nesse contexto, os hotéis que não aprimorarem a qualidade, a diversidade de serviços, as práticas e os sistemas de gestão de custos com objetivo de gerar desempenho superior, estarão diante de ambiente mais adverso para sobreviver. De acordo com Andrade, Brito e Jorge (2000, p.24), a concorrência se torna mais acirrada, com conseqüente diminuição das tarifas e forte melhora do padrão de atendimento ao hóspede, o qual deve ser constantemente aprimorado.

Considerando esse cenário, a capacidade de sobreviver no longo prazo está condicionada à competência do hotel de gerenciar cenários futuros de forma dinâmica e eficaz. Conseqüentemente, é fundamental a precisão na condução das metas e estratégias e, para tanto, são necessários sistemas que possam dar sustentabilidade ao processo decisório. Os hotéis que entendem a necessidade de criar valor têm como grande desafio encontrar formas de operacionalizar os novos métodos de gestão, como os relacionados a custos. Assim sendo, há necessidade de soluções que atendam melhor às necessidades dos gestores hoteleiros por 
informações confiáveis que assegurem ações de melhoria nas operações, objetivando gerar maior efetividade, eficiência e economia.

Tradicionalmente, os pequenos negócios hoteleiros executam suas atividades com poucas informações efetivas sobre os custos, o que resulta em deficiências na gestão e nas ações de melhoria. Um dos papéis mais importantes do gestor é o de auxiliar na determinação do custo do produto e serviço produzido, vendido ou prestado pelo hotel. A informação de custo é igualmente importante em toda a cadeia de valor. As decisões tomadas por gerentes da recepção, reservas e marketing, compras, recursos humanos, governança, finanças e administração, são influenciadas pelo custo dos produtos e serviços.

Em ambiente competitivo, os gerentes devem estar atentos ao impacto das decisões financeiras e estratégicas no sucesso global do negócio. Por exemplo, o gerente de reserva e marketing precisa estabelecer um preço de diária competitivo que capte boa parte dos hóspedes a fim de gerar o lucro desejado. Para que isso aconteça é necessário determinar o volume de custos fixos e variáveis e o conseqüente ponto de equilíbrio. Assim também o gerente de compras deve tomar a decisão entre adquirir os produtos prontos ou mandar fabricá-los, como, por exemplo, contatar uma fábrica para produzir as toalhas de banho personalizadas ou adquiri-las no mercado na forma padrão. Comparar então os dois custos é de fundamental importância na tomada dessa decisão. É claro que o hotel ainda deve considerar fatores qualitativos, como a aparência e a qualidade da toalha e, principalmente sua estratégia de negócio.

Assim, é possível que a atividade mais importante do gestor seja justamente criar e manter o sistema de custos. As vantagens advindas da gestão de custos são: (i) a detecção de desperdícios; (ii) a inclusão de novos controles de custos para cobrir riscos potenciais que venham a surgir de novas situações; (iii) a melhora da competitividade global do hotel. Para avaliar custos corretamente, o gestor deve ter um conhecimento de sua composição: se fixo, variável, semi-fixo ou semi-variável. Este conhecimento deve estender-se para outros aspectos, como métodos de custeamento mais adequados e controles estratégicos e operacionais.

Nesse contexto, surge a pergunta que orienta esta pesquisa: quais são as informações de custos utilizadas em empresas hoteleiras na cidade de Florianópolis (SC)? A partir deste 
questionamento delineia-se o objetivo central do artigo, que é o de apresentar uma pesquisa sobre a existência de informações de custos em empresas hoteleiras.

\section{Desenvolvimento do Tema}

Inicialmente é desenvolvida a base conceitual para o estudo proposto sobre informações de custos, quando se discorre sobre os principais métodos de custeamento. Na seqüência são apresentados os estudos sobre análise custo/volume/lucro, margem de contribuição e ponto de equilíbrio, bem como sobre centros de responsabilidade e formação do preço da diária.

\subsection{Informação de custos}

Independentemente do tipo de hotel estudado, o custo geralmente é associado à venda do produto (refeição) gerado ou serviço (hospedagem) prestado. Embora possa parecer simples determinar o custo de um produto ou serviço, tal processo geralmente é bem complexo. Neste sentido, a informação de custos pode trazer consigo variadas utilidades e configurações, conforme as diferentes propostas de atendimento a usuários distintos.

Por décadas, a informação financeira para elaboração dos relatórios contábeis foi o foco principal dos sistemas de custo. Pela contabilidade de custos o objetivo básico é conhecer o custo do produto ou serviço e, a partir desta noção, determinar o valor dos estoques na elaboração do Balanço Patrimonial, ou o custo dos produtos vendidos ou serviços prestados na Demonstração do Resultado do Exercício, objetivando assim apurar o lucro e, conseqüentemente, o pagamento de tributos, dividendos e participações. Neste caso, o custo deve ser determinado de acordo com os princípios contábeis, leis e normas, conforme figura 1. 


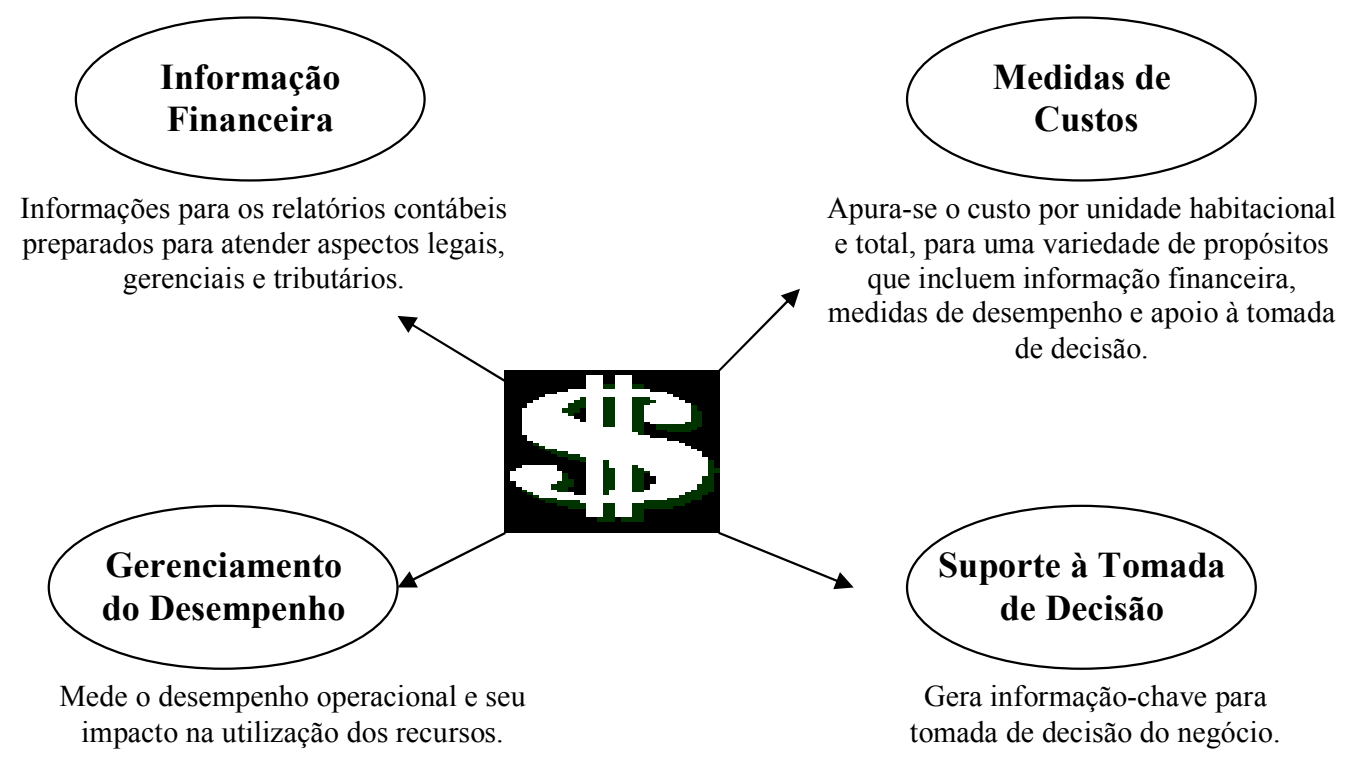

Figura 1- Função dos sistemas de custos

Fonte: Adaptado de Oliver, 2004.

O hotel ainda pode requerer o custo total ou por unidade habitacional para uma variedade de diferentes propósitos, como avaliar produtos, serviços, hóspedes, eventos, projetos, programas, departamentos ou áreas de trabalho, entre outros. A informação de custo é igualmente importante para determinar o mix de serviços e a rentabilidade proporcionada por cada hóspede. Assim, o objetivo é saber o custo do serviço em particular para determinar o preço da diária ou calcular sua rentabilidade unitária.

Outrossim, a informação de custos pode ser utilizada para projetar o futuro. Neste caso, o hotel pode determinar o custo da unidade habitacional de acordo com sua relevância na tomada de decisão. Assim tomada, a informação do custo é fundamental no planejamento e controle das atividades, atingindo o processo orçamentário e, portanto, a avaliação de desempenho. O sistema de custos também fornece informações fundamentais para a tomada de decisão, como executar ou transferir a terceiros os serviços e investimentos de capital, entre outros.

Para melhor entendimento das informações geradas pelo sistema de custos, são apresentados os principais métodos de custeamento, direto ou variável, por absorção e por atividades, e exposta uma apreciação das relações entre o preço e o custo, o volume de vendas e ocupação e o lucro, denominada análise custo/volume/lucro. 


\subsection{Métodos de custeamento}

Os métodos de custeamento se constituem basicamente em sistemas de informação. Os métodos requerem dados, como materiais utilizados, horas de mão-de-obra direta, custos indiretos e número de pernoites vendidos. Destes dados são derivados os custos do produto ou serviço e outras informações, de acordo com os objetivos e a metodologia utilizada. A seguir serão abordados os principais métodos de custeamento, conforme mencionados no item anterior.

\subsubsection{Custeio direto ou variável}

O custeio variável mensura o custo de um produto ou serviço de acordo com os recursos variáveis usados para produzi-lo ou executá-lo. Se o hotel entende que a melhor forma de custeio para seus produtos ou serviços é o custeio direto, o sistema somente apurará os custos relacionados diretamente aos produtos ou serviços. Entre outros, podem ser considerados objetos de custos a hospedagem ou as refeições e bebidas. Desta forma, no custeio direto ou variável, são considerados os custos que variam diretamente em relação ao nível de atividade do hotel. Os custos fixos indiretos não são alocados aos produtos ou serviços, devendo ser tratados como despesas do período.

As informações geradas por esse método podem ser altamente valiosas na tomada de decisão. Este tipo de custeio pode ser importante em hotéis com parcela de custos variáveis significativas, no entanto, em hotéis em que os custos fixos formam a maior parte dos custos totais, seu uso pode levar a decisões tomadas sobre dados pouco relevantes. Ao longo do tempo, em muitos hotéis, os custos fixos vêm se tornando a maior parte do custo total; daí que este método tem perdido espaço e relevância de utilização.

\subsubsection{Custeio por absorção}

O custeio por absorção, também conhecido como custeio integral ou custeio por absorção integral, aloca somente os custos de produção e execução aos produtos ou serviços. Para Crepaldi (1998), o custeio por absorção consiste na apropriação de todos os custos, sejam eles fixos ou variáveis, à produção e execução do período. As despesas são lançadas diretamente no resultado do exercício, conforme ilustra a figura 2. 


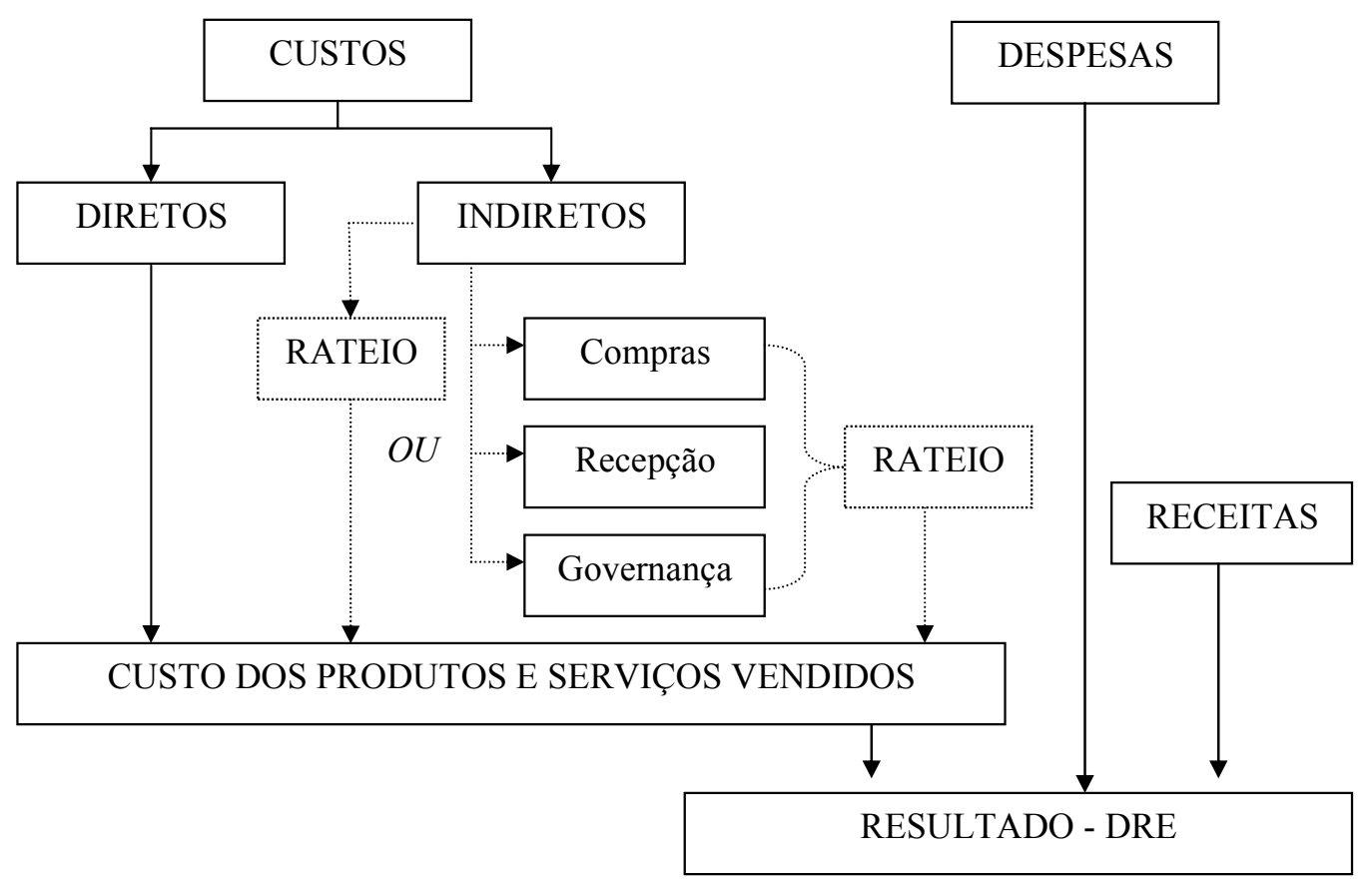

Figura 2- Esquema básico do método de custeio por absorção

Fonte: Adaptado de MARTINS, 2000.

O custeio por absorção considera apenas os custos, sejam eles diretos ou indiretos, para a formação do custo total do produto ou serviço. Assim, os custos com materiais diretos e mãode-obra direta são alocados diretamente no produto ou serviço. Já os custos indiretos podem ser alocados de duas formas: (i) rateados diretamente pelos produtos ou serviços do hotel, (ii) ou alocados nos departamentos ou centros de custo para, posteriormente, serem rateados pelos produtos ou serviços, conforme demonstrado na figura 2.

O custeio por absorção é muito criticado por estudiosos e especialistas em custos, em conseqüência da utilização de formas inadequadas de rateio dos custos indiretos, o que realmente pode comprometer os resultados gerados pelo método. Tal problemática decorre do crescimento do montante dos custos indiretos frente aos custos diretos (materiais e mão-deobra direta), em função das mudanças nos processos de execução e do avanço da tecnologia.

\subsubsection{Custeio baseado em atividades}

No passado, os custos indiretos - CI - normalmente representavam uma parcela irrelevante do custo total de um produto ou serviço. O cenário do negócio era basicamente formado por 
trabalho manual, cuja mão-de-obra e materiais compunham a maior parcela do custo total, conforme esquematizado na figura 3. Como a mão-de-obra direta representava o maior valor em relação aos custos totais, era lógico utilizá-la como base para ratear os CI entre produtos e serviços. Tais procedimentos eram aceitáveis pela pouca representatividade dos CI, fato que possivelmente acarretava pequenas distorções (JACKSON e SAWYERS, 2001).

De acordo com Castelli (2000), tradicionalmente um hotel gera gastos muito pequenos com Excluído: $<$ sp $><$ sp $>$ materiais, mas elevados com mão-de-obra; além de custos fixos expressivos decorrentes de depreciação do imóvel e considerável quantidade de equipamentos. Com a necessidade de modernização, os CI gerados pelo uso de máquinas e softwares tornaram-se ainda maiores. Para Jackson e Sawyers (2001), em ambientes empresariais fortemente automatizados, os custos de mão-de-obra direta diminuíram em relação aos custos totais, ao mesmo tempo em que os CI subiram para $60 \%$ ou mais (figura 3 ).

Figura 3 - Mudança nos percentuais dos custos totais Fonte: Adaptada de Jackson e Sawyers, 2001.

Para Weygandt, Kieso e Kimmel (2002), as últimas décadas produziram significativas mudanças nas empresas. Os avanços em sistemas computadorizados, inovações tecnológicas, competição global e automatização mudaram drasticamente o ambiente empresarial. Como resultado, enquanto a quantidade de mão-de-obra direta usada em muitos hotéis diminuiu, o total dos custos indiretos decorrentes de depreciação de equipamentos e máquinas, materiais indiretos e manutenção, aumentou significativamente. Esses custos não podem mais ser apropriados com base somente na mão-de-obra direta, então, as empresas que continuam usando tal base de alocação podem estar distorcendo os custos de seus produtos ou serviços.

Para Turney (1993), e a exemplo do custeio por absorção, a informação do custeio tradicional é como um navio num mar de icebergs. Na superfície todos aparentam ser pequenos e tranqüilos, ou seja, produtos ou serviços não rentáveis ou processos improdutivos não são indícios de desperdício nas operações. No entanto, abaixo da superfície se esconde o perigo, com produtos e serviços de qualidade inferior, custo alto, preços maiores que a concorrência, mercados negligenciados e produtos e serviços que não atendem às necessidades dos hóspedes. 
As empresas, reconhecendo que há distorções na alocação dos custos indiretos com base na mão-de-obra direta, têm utilizado outros critérios como base para alocar os custos indiretos. No entanto, o uso de um único critério também pode gerar distorções na alocação dos custos indiretos. Se o processo empresarial for complexo, então somente bases de alocação múltiplas resultam em um custo por unidade mais preciso. Em tais situações, os gerentes precisam considerar um novo método de alocação dos custos indiretos que utilize bases múltiplas (WEYGANDT, KIESO e KIMMEL, 2002).

O Custeio Baseado em Atividades aloca os custos indiretos nas atividades e das atividades nos objetos de custo por meio de direcionadores. Segundo Nakagawa (2001), o Activity-Based Costing (ABC) é uma metodologia desenvolvida para facilitar a análise estratégica de custos relacionados com as atividades que mais impactam o consumo de recursos do hotel. Martins (2000) define o ABC como uma ferramenta que permite melhor visualização dos custos através da análise das atividades executadas no hotel e suas respectivas relações com os produtos ou serviços.

$\mathrm{O} \mathrm{ABC}$ direciona os recursos indiretos às atividades e daí aloca os custos destas atividades nos produtos e serviços por meio de direcionadores de atividades (aqui, os produtos e serviços são chamados de "objetos de custo"). Assim, as atividades terminam por consumir os recursos que foram alocados nos objetos de custos ("produtos e serviços”), conforme figura 4.

\section{RECURSOS}

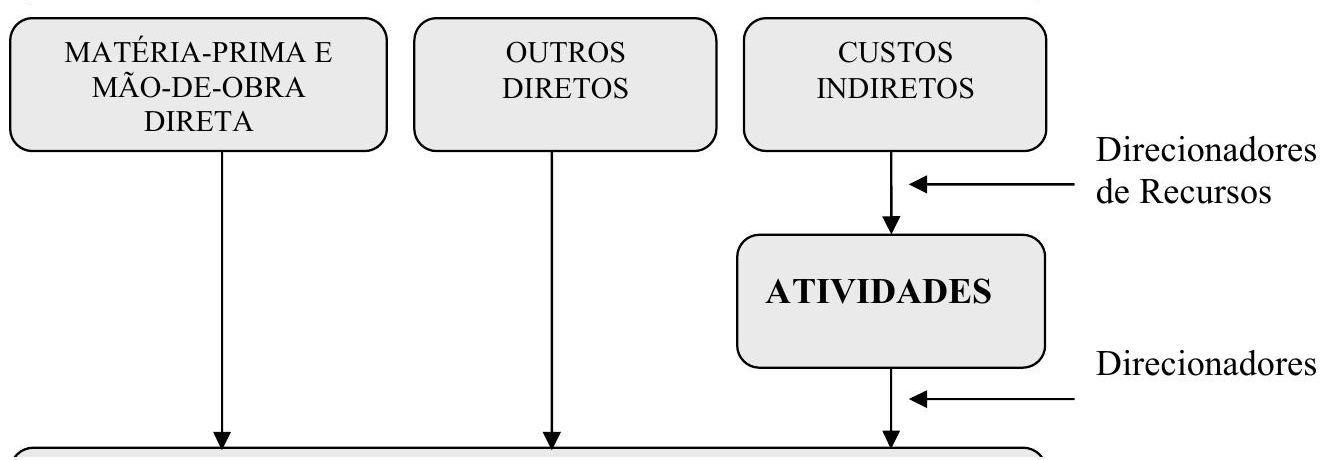


Figura 4 - O modelo de decomposição simples dos custos Fonte: Os autores.

O ABC primeiramente aloca custos nas atividades e em seguida os destina para custos dos produtos e serviços, tendo como base a quantificação de seu uso naquelas atividades. $\mathrm{O}$ raciocínio por trás do $\mathrm{ABC}$ é muito simples: produtos e serviços consomem atividades e atividades consomem recursos.

Para Zimmerman (2000), quando a empresa desenvolve o custeio baseado em atividades, a primeira tarefa consiste na análise dos tipos de fatores que geram os custos em cada departamento, por exemplo, recepção, compras, manutenção e controle de qualidade. Os analistas de custo examinam cada departamento do hotel para entender quais os fatores que estão a acarretar custos.

A implementação do custeio baseado em atividades apresenta inúmeros benefícios e limitações, que segundo Weygandt, Kieso e Kimmel (2002) são:

- otimização da alocação dos custos;

- melhora no controle dos custos indiretos;

- maior eficácia na tomada de decisão;

- menos econômico em sua implementação;

- não soluciona por completo a problemática da alocação dos custos indiretos.

O custeio baseado em atividades vem sendo implementado por um número cada vez maior de empresas, principalmente de serviços. 


\subsection{Análise custo/volume/lucro - CVL}

A análise custo/volume/lucro consiste no estudo dos efeitos de mudanças nos custos e do nível de atividade sobre a lucratividade do hotel. A análise focaliza as interações entre os elementos preço do produto e serviço, volume ou nível de atividade, custos variáveis por unidade, custos fixos totais e quantidade de refeições e outros produtos e serviços. Sendo assim, o CVL proporciona um exame sistemático das relações entre preços das diárias, níveis de ocupação, custos, despesas e lucros.

A análise do CVL é importante para o planejamento do lucro, auxiliando os gestores a gerenciar as inter-relações entre os elementos que o compõem. Ainda constitui-se em fator crítico para a tomada de decisão sobre formação do preço das diárias, determinar o conjunto de produtos e serviços e maximizar o uso da infra-estrutura do hotel, entre outros.

A análise de custo/volume/lucro conduz a dois importantes conceitos: margem de contribuição e ponto de equilíbrio.

\subsubsection{Margem de contribuição}

A margem de contribuição é o valor da receita que permanece depois da dedução dos custos e despesas variáveis. É freqüentemente calculada com base na unidade habitacional do hotel.

Para Padoveze (1997), a margem de contribuição representa o lucro variável, sendo a diferença entre o preço da diária e os custos e despesas variáveis por unidade habitacional. Significa que em cada unidade ocupada no hotel, após a absorção de todos os custos e despesas variáveis, é revelado um valor que, multiplicado pelo total de unidades ocupadas, apresenta a contribuição marginal do produto ou serviço para o hotel.

Fórmula: $\quad \mathrm{MC}=\mathrm{PD}-(\mathrm{CV}+\mathrm{DV})$

O índice da margem de contribuição mede o efeito sobre o lucro operacional decorrente do aumento ou diminuição do nível de ocupação das unidades habitacionais.

\subsubsection{Ponto de equilíbrio}

Uma relação fundamental na análise do CVL é o nível de ocupação em que as receitas totais são iguais aos custos totais (fixos e variáveis). Este nível de ocupação é chamado break-even point, ou "ponto de equilíbrio". Neste nível de atividade o hotel não terá lucro nem prejuízo 
(figura 5). O cálculo do ponto de equilíbrio é útil na tomada de decisão sobre alterações nas unidades habitacionais, mudança nos preços das diárias etc.

Ainda segundo Padoveze (1997), em termos quantitativos o ponto de equilíbrio evidencia o nível de ocupação do hotel para conseguir pagar todos os custos e despesas fixas, além dos custos e despesas variáveis que ele tem necessariamente que incorrer para prestar o serviço. No ponto de equilíbrio não há lucro ou prejuízo. A partir desse nível de ocupação é que o hotel passa a gerar lucro.

Quantificado, o ponto de equilíbrio objetiva determinar o número mínimo de unidades habitacionais que devem ser ocupadas no hotel para que não haja prejuízo.

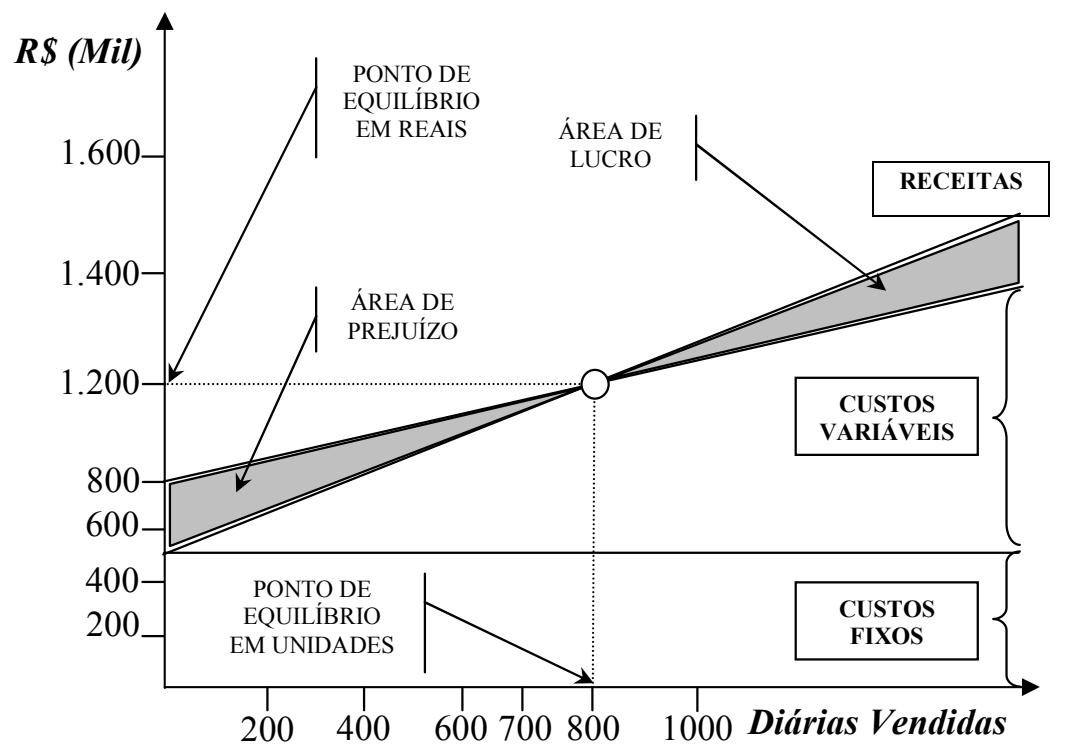

Figura 5 - Ilustração do ponto de equilíbrio

Fonte: Os autores.

Em determinadas situações nota-se que o hotel possui tipos de produtos e serviços diferentes, implicando dificuldade de obtenção do conjunto ideal de unidades. Além disto, existem ainda problemas na identificação dos custos e despesas fixas para cada unidade habitacional, sendo que, para tanto, deve-se utilizar uma informação de caráter global expressa em valor monetário. Assim pode-se determinar o valor mínimo em unidades monetárias que deve ser obtido para que o hotel não tenha prejuízo.

\subsubsection{Ponto de equilíbrio usando ABC}


$\mathrm{O}$ ponto de equilíbrio calculado pelo $\mathrm{ABC}$ requer algumas pequenas modificações em relação à fórmula geral apresentada anteriormente. A análise do CVL convencional assume que todos os custos são variáveis ou fixos. Já no $\mathrm{ABC}$, os custos são classificados por unidade e organizacional, para a análise adequada do CVL. Para tanto se considera que, em nível de unidade, os custos tenham um comportamento diretamente variável em relação ao volume e, que em nível organizacional, os custos são globais e, portanto, apresentam um comportamento fixo, enquanto que, em nível de unidade, estes custos provavelmente variem de acordo com os direcionadores relacionados à sua complexidade e diversidade. Assim, juntamente com os custos fixos, também são incluídos no cálculo os custos em nível de unidade no numerador da fórmula do ponto de equilíbrio. Embora possa parecer que o valor do CVL diminua usando $\mathrm{ABC}$, na realidade, desta forma ele pode ser até mesmo mais útil na tomada de decisão, porque a informação do comportamento dos custos no sistema $\mathrm{ABC}$ é mais precisa (JACKSON e SAWYERS, 2001).

$$
\begin{array}{r}
\mathrm{PE}=\text { Custos em Nível Organizacional + Unidade } \\
\text { Margem de Contribuição por Pernoite }
\end{array}
$$

\subsection{Centros de Responsabilidade}

Para Anthony e Govindarajan (2002), centro de responsabilidade é simplesmente uma unidade do hotel sob supervisão de um gestor responsável por suas atividades. O centro é responsável pelo desempenho de alguma função, que é seu produto, e pela aplicação de recursos ou insumos, de forma eficiente. Com base na dimensão de entradas e saídas, estes centros podem ser classificados em quatro tipos: centros de receita, centros de custos, centros de lucro e centros de investimentos.

\subsubsection{Centros de receita}

O gestor do centro de receita tem o controle e a responsabilidade sobre a receita atribuída à unidade, mas não sobre os custos. Nos centros de receita, as saídas são medidas em termos financeiros e não-financeiros, mas nenhuma tentativa formal é feita para relacioná-las com as entradas. Um exemplo típico de centro de receita em hotel é o setor de reservas.

\subsubsection{Centros de custo}


O centro de custo controla e responde pelos recursos utilizados, mas não diretamente pelas receitas ou ao nível do investimento. Os gestores dos centros de custo têm autoridade e responsabilidade na gestão dos gastos. Estes centros podem ser formados por unidades de manutenção e de apoio que não produzem um produto ou serviço final, ou quando a mensuração das saídas se torna difícil. Por exemplo, podem ser considerados prováveis centros de custos o departamento de compras, de manutenção, de recursos humanos ou a contabilidade de um hotel.

\subsubsection{Centros de lucro}

Os gestores dos centros de lucro controlam e são responsáveis pelos custos incorridos e pela receita gerada. Nestes centros, os gestores são avaliados pelo resultado gerado pela unidade. Para Atkinson et al. (2000), um centro de lucro é como um negócio independente, exceto que a administração, e não o gerente do centro de responsabilidade, é quem controla o nível de investimento na unidade. Por exemplo, no hotel um centro de lucros pode ser o bar ou restaurante.

\subsubsection{Centros de investimento}

Como um centro de lucro, o centro de investimento incorre em custos, gera receitas e avalia os investimentos. Assim, por ele também são controlados o uso e aplicação de recursos permanentes. Estes centros podem ser considerados unidades independentes, as quais geralmente são utilizadas por hotéis que descentralizam totalmente a tomada de decisão. Por exemplo, a unidade hoteleira pode ser considerada um centro de investimentos, desde que na sua gestão sejam controlados os custos e receitas e avaliados os investimentos.

\subsection{Formação do preço da diária}

A seguir apresentam-se os principais métodos utilizados na formação do preço, segundo Santos (1995).

\subsubsection{Método baseado no custo}

Em grande parte dos segmentos de mercado, o custo continua sendo o referencial na definição do preço (KOTLER, 2000). Entretanto, na hotelaria é extremamente importante também 
considerar o retorno sobre investimentos. O problema desses métodos de formação do preço da diária é o fato de desconsiderar fatores importantes, como: retorno sobre investimentos, concorrência, o mercado e o hóspede.

\subsubsection{Método baseado nas decisões dos hotéis concorrentes}

Qualquer método de determinação de preços deve ser comparado com os preços dos hotéis concorrentes que porventura atuem no mercado. Este método pode ser desdobrado em:

- método de preços correntes - parte dos hotéis do setor utilizam preços similares;

- método de imitação de preços - preço baseado em concorrente forte no mercado;

- método de preços agressivos - preços menores que os concorrentes, com objetivo de se estabelecer rapidamente ou tirá-los do mercado;

- método de preços promocionais - alguns produtos ou serviços são colocados a preços menores ou até a preço de custo.

\subsubsection{Método baseado nas características do mercado}

Com base no conhecimento do mercado o hotel pode estabelecer seus preços, considerando fatores ambientais, objetivos e demanda etc. Diante disso, ele pode optar em atender determinada classe social com um tipo específico de produto ou serviço, considerando aqueles atributos na formação do preço.

\subsubsection{Método misto}

O método misto para a formação de preços inclui a combinação dos seguintes fatores:

- custos envolvidos;

- decisões da concorrência;

- características do mercado.

A determinação do preço da diária para determinados segmentos de mercado tornou-se complexa devido a hóspedes cada vez mais exigentes. 


\section{Metodologia de Pesquisa}

Com o objetivo de responder ao problema proposto neste trabalho, optou-se por uma abordagem de pesquisa descritiva que, segundo Gil (1999), tem como principal objetivo descrever características de determinada população. A população corresponde aos meios de hospedagem, seja qual for a sua denominação: hotel, resort, pousada, apart hotel, flat ou condohotel, entre outras, que, segundo a Embratur (Instituto Brasileiro de Turismo), são todos considerados meios de hospedagem. O delineamento adotou uma perspectiva empíricoanalítica de caráter quantitativo e qualitativo. A pesquisa ficou delimitada a 150 empresas hoteleiras localizadas em Florianópolis (SC) que são aquelas registradas no Sindicato de Hotéis, Restaurante e Similares da Grande Florianópolis-SC, classificadas por número de empregados de acordo com relação obtida junto ao Serviço de Informações Empresariais da Federação das Indústrias do Estado de Santa Catarina - FIESC.

Foi escolhida a cidade de Florianópolis (SC) para realização da pesquisa por representar importante centro de investimento da área de hotelaria, em razão das inúmeras praias e ser considerada uma cidade com a melhor qualidade de vida, além de, segundo a ABIH, ser a quinta maior cidade brasileira em número de unidades habitacionais disponíveis.

Quanto aos instrumentos, a pesquisa é considerada do tipo levantamento ou survey, a qual, de acordo com Gil (1999), caracteriza-se pela interrogação direta das pessoas ou empresas cujo comportamento se deseja conhecer. Desta forma, para realizar a pesquisa foram utilizados questionários estruturados com 15 questões fechadas de múltipla escolha, mais duas questões abertas. Estes questionários foram entregues pessoalmente ou enviados por e-mail aos hotéis durante o mês de maio de 2006. Do total de 150 questionários enviados, 60 hotéis responderam às questões (ver quadro 1 ), representando $40 \%$ do total.

Quadro 1- Número de hotéis por porte que responderam ao questionário

\begin{tabular}{|c|c|c|c|}
\hline Porte da Empresa & Número de Empregados & $\begin{array}{c}\text { Total da } \\
\text { Amostra }\end{array}$ & Total \\
\hline Micro & Até 19 & 40 & 1 \\
& & & 5 \\
Pequena & 20 a 99 & 19 & 3 \\
\hline
\end{tabular}




\begin{tabular}{|l|c|c|l|} 
& & & 4 \\
Média & 100 a 499 & 0 & 0 \\
Grande & Acima de 500 & 1 & 1 \\
\hline
\end{tabular}

Em termos de tamanho, 66,5\% dos hotéis que responderam ao questionário possuem até 19 empregados, $32,5 \%$ possuem entre 20 e 99 empregados, e apenas $2 \%$ possuem mais do que 500 empregados. Portanto, estes dados constituem-se em uma amostra de acessibilidade.

Assim sendo, pode-se cumprir o objetivo do artigo que é o de apresentar uma pesquisa sobre a utilização de métodos de custeio, centros de custos e outras informações de custos em empresas hoteleiras de Florianópolis (SC), comparado-a com os resultados obtidos no Estado do Rio Grande do Norte e região Nordeste. Para proceder à comparação de alguns itens serão utilizados dados de pesquisa realizada por Silva (2000) em hotéis do Nordeste, Lima, Egito e Silva (2002) no Estado do Rio Grande do Norte, e Leitão e Silva (2006) na região Nordeste.

\section{Resultados da Pesquisa}

\subsection{Métodos de custeamento}

Pesquisa realizada num universo de 150 hotéis (60 respostas) na cidade de Florianópolis (SC) revelou que 24 deles utilizam algum sistema de custos. Os métodos de custeamento mais utilizados são o por Atividades-ABC (50\%) e o Direto ou Variável (45\%), conforme gráfico 1 .

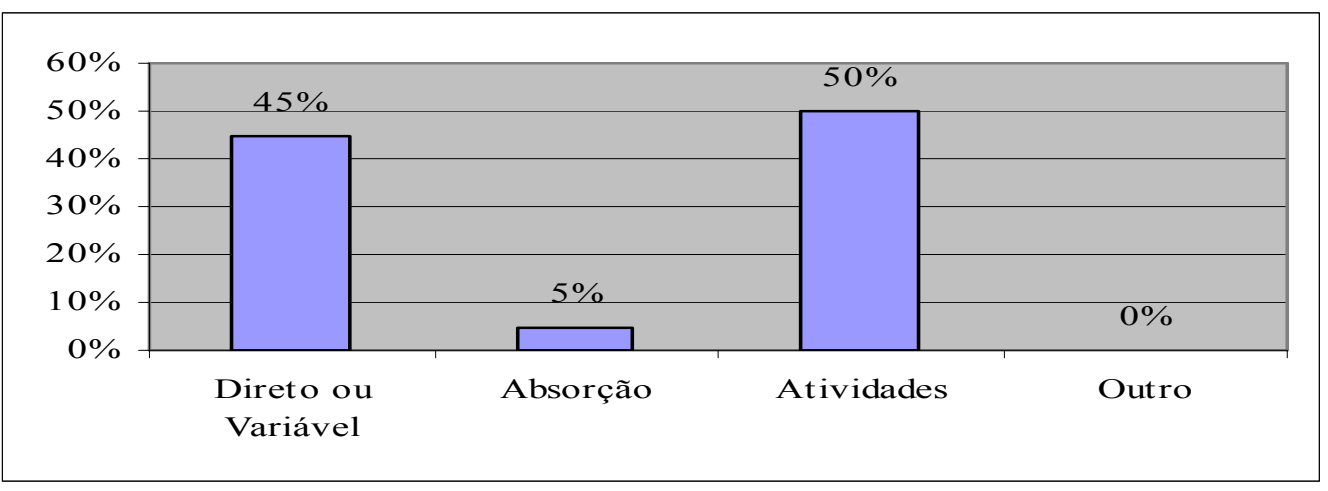

Gráfico 1- Resultado quanto aos métodos de custeamento 
Fonte: Pesquisa de campo, 2006.

A pesquisa realizada por Lima, Egito e Silva (2002) no Rio Grande do Norte revelou que 62,5\% dos hotéis usavam o método por Absorção, enquanto 25\% o Direto ou Variável, mas apenas $6,25 \%$ o por Atividades-ABC. A pesquisa realizada por Silva (2000) em hotéis do Nordeste apresentou dados semelhantes, com 67,9\% que utilizavam o Absorção e 25,93\% o Direto ou Variável. Já a pesquisa realizada por Leitão e Silva (2006) reflete a predominância no Nordeste do custeio por Absorção com 72,1\%, do Direto ou Variável com 24,5\%, e do por Atividades com 3,4\%.

\subsection{Utilização de centros de responsabilidade}

Para tornar possível a avaliação dos gestores pode-se dividir o hotel em unidades, divisões e departamentos e atividades, denominados centros de responsabilidade (conforme mencionado no item 2.4). Há quatro tipos básicos de centros de responsabilidade: centro de receita, centro de custo, centro de lucro e centro de investimento. Estes centros indicam o grau de responsabilidade que o gerente possui com o desempenho da unidade.

Na utilização dos centros de responsabilidade, a pesquisa revelou que 57\% dos hotéis não procedem a qualquer avaliação de desempenho por meio de centros de responsabilidade formais, enquanto $28 \%$ utilizam centros de custos na atribuição de responsabilidades, conforme gráfico 2 .

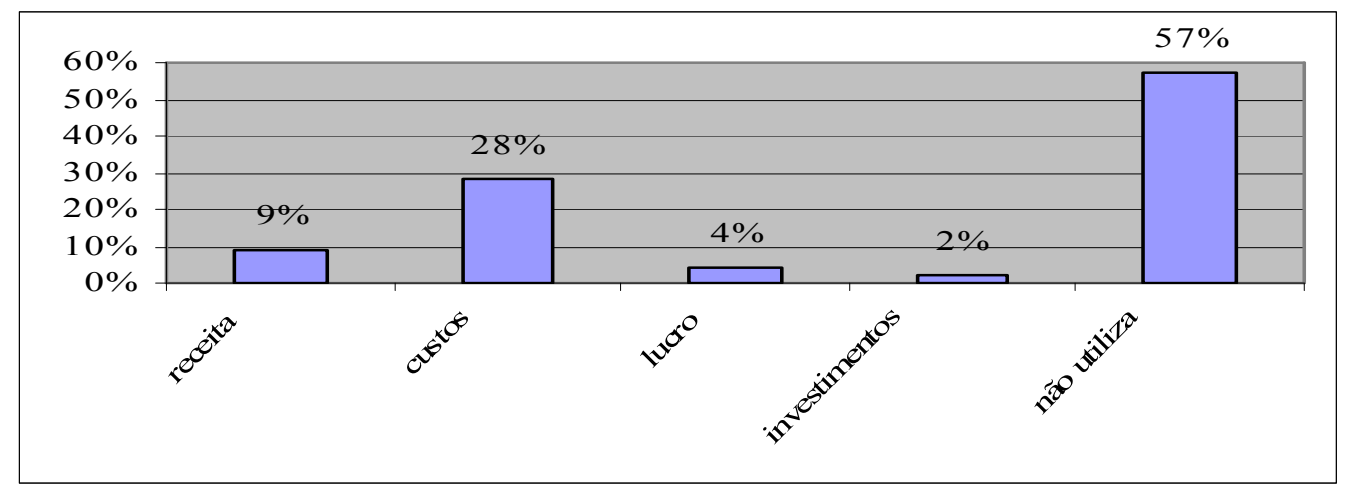

Gráfico 2 - Resultado quanto a utilização de centros de responsabilidade Fonte: Pesquisa de campo, 2006. 
Quanto à pesquisa realizada no Rio Grande do Norte por Lima, Egito e Silva (2002), a mesma aponta que a maioria, 78,13\%, utiliza centro de custos. Entretanto a do Nordeste, feita por Silva (2000), fica em posição intermediária, apresentando $51,86 \%$ de hotéis com presença de centros de custos.

\subsection{Conhecimento do ponto de equilíbrio}

Com 46 respostas, destacam-se 15 hotéis que, com metade das unidades habitacionais ocupadas (em média, por dia), ultrapassam o ponto de equilíbrio, conforme demonstrado no gráfico 3 .

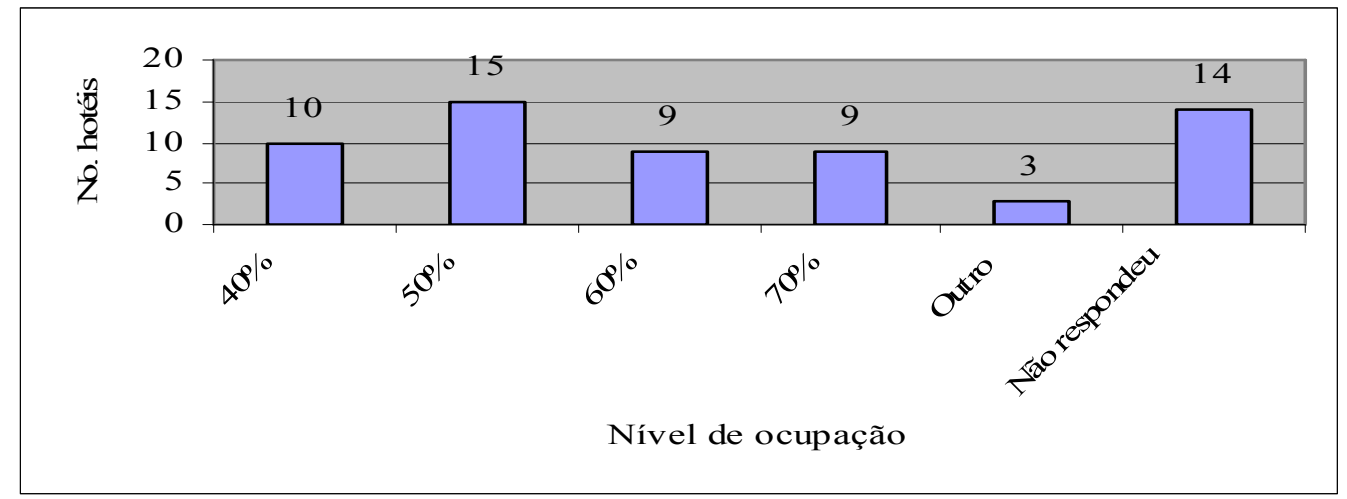

Gráfico 3 - Resultado quanto ao ponto de equilíbrio

Fonte: Pesquisa de campo, 2006.

Destaque também para os hotéis de porte micro, entre os quais $67 \%$ atingem o ponto de equilíbrio com menos da metade das unidades habitacionais ocupadas.

\subsection{Formação do preço da diária}

Conforme apresentado no item 2.5, o hotel pode utilizar diferentes formações do preço da diária, dependendo da estratégia de posicionamento escolhida.

Questionados quanto às informações utilizadas na formação do preço da diária, apenas $15 \%$ dos hotéis pesquisados utilizam custos. Os métodos mais empregados na formação do preço da diária são os baseados na concorrência, com $31 \%$, e mercado e misto, com $27 \%$, conforme gráfico 4 . 


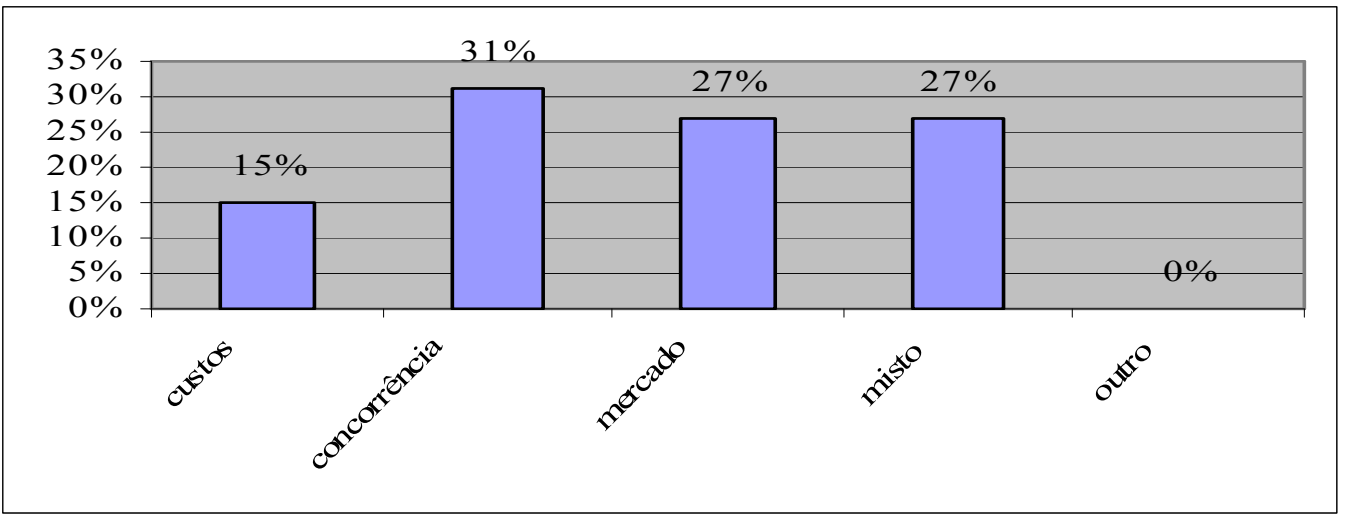

Gráfico 4 - Resultado quanto a formação do preço de venda Fonte: Pesquisa de campo, 2006.

A formação dos preços de venda das diárias obedece a vários métodos e estratégias; no entanto, a mais antiga e, conseqüentemente, a mais usada, é a formação de preços por meio de preços por meio da apuração dos custos dos produtos ou serviços. No mercado, o preço exerce grande influência na decisão de compra; portanto os hotéis devem ter cuidado na sua determinação. Entre os inúmeros métodos e estratégias de formação de preço da diária, é conveniente escolher aquele que possibilita compatibilizar o crescimento da receita com a lucratividade.

\section{Análise dos Resultados}

Foi surpreendente o número de hotéis que não utilizam qualquer sistema de custos: entre os micro-hotéis, este número corresponde a $62 \%$ e, entre os pequenos, equivale a $50 \%$.

A escolha do método de custeio torna-se fundamental na melhoria dos processos de negócio e eliminação dos desperdícios. A informação de custos pode ser o diferencial nesse mercado competitivo. Entre os hotéis que possuem sistemas de custeio, 7 dos micros utilizam o Variável e 6 o por Atividades: por outro lado, nos pequenos o Variável é utilizado por 3, o Absorção por 1 e o por Atividades por 4 hotéis, conforme tabela 1. 
Tabela 1- Distribuição dos métodos de custeio em relação ao porte do hotel

\begin{tabular}{|l|c|c|c|}
\hline Porte & Variável & Absorção & Atividades \\
\hline Micro & 7 & 0 & 6 \\
\hline Pequena & 3 & 1 & 4 \\
\hline Grande & 0 & 0 & 1 \\
\hline
\end{tabular}

Fonte: Pesquisa de campo, 2006.

Outro destaque foi a diferença entre as pesquisas quanto ao método utilizado. Considerando a realizada na região Nordeste, na mesma houve a utilização do custeio por Absorção por 67,9\%, enquanto na realizada em Florianópolis o custeio baseado em Atividades foi citado por $50 \%$ dos hotéis. Já o custeio por Absorção corresponde a 5\% dos hotéis pesquisados. Tal diferença pode sugerir várias explicações, entre outras podem ser destacadas:

- os hotéis estão buscando novas metodologias de custeamento na tentativa de gerenciar melhor seus custos, já que o $\mathrm{ABC}$ é considerado mais adequado neste quesito;

- a resistência à aplicação do custeio por Absorção em Florianópolis se deve provavelmente por ser um sistema principalmente praticado em empresas industriais, o qual costuma apresentar problemas de implementação em empresas de serviço;

- o Fisco não exige este sistema das empresas de serviço (o $\mathrm{ABC}$ não é aceito pelo Fisco);

- diferenças regionais decorrentes de aspectos de mercado, da concorrência, de sazonalidade, culturais e sociais.

O gestor do centro é avaliado pela capacidade de gerenciar a unidade de sua responsabilidade. Neste quesito, $57 \%$ dos hotéis não utilizam centros de responsabilidade na sua gestão. Os hotéis do Nordeste revelam resultados melhores: aproximadamente 52\% das empresas apresentam centros de custos, enquanto em Florianópolis apenas 28\% utilizam esta sistemática. Fica uma questão em aberto: como os hotéis avaliam seus empregados se não geram informações por centro de responsabilidade?

Conjecturando, essa avaliação pode dar-se por meio do processo orçamentário, comparando as metas orçadas com o realizado, seguida da análise das variações ocorrentes. Quanto ao orçamento, por exemplo, $26 \%$ o utilizam em micro e pequenos hotéis e $100 \%$ nos grandes 
empreendimentos hoteleiros. Por outro lado, na avaliação de desempenho, por exemplo, apenas um hotel utiliza a ferramenta Balanced Scorecard.

Relativamente ao ponto de equilíbrio, $67 \%$ dos micro-hotéis conseguem atingi-lo com metade ou menos das unidades ocupadas. Isto se deve em parte a uma estrutura simplificada, com administração familiar e poucos serviços oferecidos aos hóspedes, o que exige uma quantidade menor de colaboradores e infra-estrutura.

Em um mercado competitivo, os hóspedes procuram o melhor produto e serviço ao menor preço possível. O que surpreende na pesquisa é a baixa utilização de informações de custos na formação do preço da diária. Em parte, isto talvez seja explicado pela inexistência de um sistema de custos para geração da informação (o que abrange $60 \%$ dos hotéis).

\section{Conclusão}

O objetivo deste trabalho foi atingido com a apresentação dos resultados da pesquisa realizada em hotéis na cidade de Florianópolis (SC). Inicialmente foram apresentados os resultados no gráfico 1, que relaciona os métodos de custeamento utilizados em hotéis, com destaque para o custeio baseado em atividades, $50 \%$ o utilizam, e variável ou direto, empregado por $45 \%$ das empresas hoteleiras.

Posteriormente, pelo gráfico 2 foi abordado o resultado da utilização dos centros de responsabilidade, com destaque para os centros de custos, empregados por $28 \%$ das empresas. Entretanto, no meio hoteleiro existe uma crescente demanda por informações no intuito de flexibilizar e descentralizar a tomada de decisão. Para tanto, os hotéis precisam desenvolver sistemas de medidas que permitam acompanhar e avaliar o desempenho dos gestores nos diversos centros de responsabilidade.

Na seqüência, no gráfico 3, introduziu-se o resultado do ponto de equilíbrio com o nível de ocupação que o hotel deve atingir para bater seus custos fixos e variáveis.

Ao final, no gráfico 4, foi apresentado o resultado da pesquisa quanto ao método de formação do preço da diária, destacando-se o benchmarking com a concorrência, com $31 \%$, e mercado e misto com $27 \%$ dos hotéis. 
Embora as informações de custos constituam-se em fator chave de sucesso e sua contribuição para a eficiência do negócio seja inquestionável, principalmente na avaliação de desempenho, nível de atividade exigida, formação do preço da diária e formação do resultado, entre outros, tal elemento ainda não recebe a devida atenção das empresas hoteleiras.

\section{Referências}

ABIH. 2005. Associação Brasileira da Indústria de Hotéis. Resultado da Pesquisa em Hotéis no Ano de 2005. Disponível em: <http://www.abih.com.br>. Acesso em: 26 abr 2006.

ANDRADE, N., BRITO, P.L., JORGE, W.E. 2000. Hotel: Planejamento e Projeto. 2.Ed. São Paulo: Senac.

ANTHONY, Robert N., GOVINDARAJAN, Vijay. 2002. Sistemas de Controle Gerencial. São Paulo: Atlas, 2002.

ATKINSON, Anthony A. 2000. Contabilidade gerencial. São Paulo: Atlas.

BARBETTA, Pedro A. 2004. Estatística Aplicada as Ciências Sociais. $5^{\text {a }}$.Ed.Florianópolis: UFSC.

CASTELLI, Geraldo. 2000. Administração Hoteleira. $7^{\text {a }}$. Ed. Caxias do Sul: Educs.

CREPALDI, Silvio A. 1998. Contabilidade Gerencial - Teoria e Prática. São Paulo: Atlas.

EMBRATUR - Instituto Brasileiro de Turismo. 2005. Indicadores de Resultado do Turismo no ano de 2005. Disponível em: <http://www.embratur.gov.br>. Acesso em: 08 jun 2006.

GIL, Antônio C. 1999. Métodos e Técnicas de Pesquisa Social. $5^{\text {a }}$. Ed. São Paulo: Atlas.

JACKSON, Steve, SAWYERS, Roby. 2001. Managerial Accounting: A focus on Decision Making. Orlando: Harcourt College Publishers.

KOTLER, Philip. 2000. Administração de Marketing. 10ª Ed. São Paulo: Prentice Hall.

LEITÃO, Carla R., SILVA, José D.G. 2006. Utilização do Custeio Variável no Gerenciamento de Hotéis: Uma Pesquisa no Setor Hoteleiro do Nordeste Brasileiro. São Paulo: $6^{\circ}$. Congresso de Controladoria e Contabilidade da USP.

LIMA, Gerlando A. S. F, EGITO, Meline O. T., SILVA, José D. G. 2004. Utilização de Informações de Custos no Processo Gerencial: Estudo Comparativo Entre a Hotelaria do Estado do Rio Grande do Norte e a Região Nordeste, sob a Ótica da Gestão Econômico-Financeira. São Paulo: Revista Contabilidade \& Finanças - USP. Edição Especial.

MARTINS, Eliseu. 2000. Contabilidade de Custos - Inclui o ABC. 9a. Ed. São Paulo: Atlas.

Ministério do Turismo. S/D. Disponível em: <http:॥www.turismo.gov.br>. Acesso em: 15 mai 2006.

NAKAGAWA, Masayuki. 2001. ABC: custeio baseado em atividades. 2.ed. São Paulo: Atlas. 
OLIVER, Lianabel. 2004. Designing Strategic Cost Systems-How to Unleash the Power of Cost Information. New Jersey: John Wiley \& Sons.

PADOVEZE, Clóvis Luís. 1997. Contabilidade Gerencial: Um Enfoque em Sistemas de Informação Contábil. $2^{a}$ Ed. São Paulo: Atlas.

SANTOS, Joel J. 1995. Formação do Preço e do Lucro. $4^{\text {a }}$.Ed. São Paulo: Atlas.

SILVA, José D. G. 2000. Investigação da prática da Gestão Econômica na Atividade Hoteleira. (Tese). Faculdade de Economia, Administração e Contabilidade. FEA/USP.

TURNEY, Peter B.B. 1993. Common Cents: The ABC Performance Breakthrough. Hillsboro: Cost Technology.

WEYGANDT, Jerry J., KIESO, Donald E., KIMMEL, Paul D. 2002. Managerial Accounting - Tools for Business Decision Making. 2a Ed. New York: John Wiley.

ZIMMERMAN, Jerold L. 2000. Accounting For Decision Making and Control. 3a.Ed. New York: Irwin MacGraw-Hill.

\section{Recebido em: 08/12/2006 (1 ${ }^{\mathrm{a}}$ versão) $13 / 09 / 2008$ ( $2^{\mathrm{a}}$ versão)}

Aprovado em: 07/05/2009 